\title{
Theoretical Reflection on the Reform of Physical Education in General Colleges and Universities
}

\author{
Haisheng Zou \\ Public Basic Course Department \\ Wuhan Technology and Business University \\ Wuhan, P. R. China
}

\begin{abstract}
In view of the existing problems in the teaching of physical education in colleges and universities in our country, this paper discusses the relationship between college sports and middle school physical education teaching content, the relationship between school sports and lifelong sports, the consciousness and compulsive problems in physical education and the problems of physical education objectivity research and other issues were discussed; combined with the physical health of sports, physical and mental dualism, entertainment and practicality and self-sports concept and the relationship between the reform of college physical education and other issues were considered. The purpose is to make the reform of physical education in colleges and universities more adapt to the needs of social development.
\end{abstract}

Keywords-normal high school; physical education; reform; theoretical thinking

\section{INTRODUCTION}

Social progress and the development of things from the continuous reform and innovation, and reform and innovation can achieve the desired results, to a large extent depends on the reform and innovation whether there is a solid theoretical basis. This paper makes a theoretical study on the reform and innovation of college physical education teaching, aiming at providing the corresponding theoretical basis for the reform of college physical education teaching in view of the present situation of college physical education teaching and the development of modern sports thought and the progress of social progress on university physical education. , Making it more responsive to the needs of social development.

\section{The Status Quo of EdUCATION IN GENERAL EDUCATION IN CHINA}

\section{A. Cohesion between College Physical Education and Middle School Physical Education Teaching Content}

China's sports from primary school, junior high school, high school to the university, formed a complete teaching system, college sports is in the 12 years of primary and secondary physical education on the basis of the school. Through the comparative study of middle school physical education syllabus and college physical education syllabus, it is found that there are many overlapping contents of college physical education syllabus and middle school physical education syllabus, especially in the first year of college, which is almost repetitive secondary school teaching content, The lack of new ideas, it is difficult to stimulate students on the enthusiasm of physical education.

\section{B. The Relationship between School Sports and Lifelong Sports}

Sport is a practical activity that requires people to participate in order to benefit from it. For college students, if sports are only something that is exerted on the body by external forces, it is impossible to stimulate the initiative of self- So that it can be transformed into daily life inseparable content. University is the last part of our education system as a whole, and it is also the last few years when students are going to society. Therefore, university sports are the most important physical education links with lifelong sports. So, the success of college physical education should pay attention to cultivate students' interest in sports and hobbies, to develop the habit of physical exercise as an important measure of college physical education standards. Therefore, the purpose of college physical education should not only pay attention to students during school physical exercise and its effect, but also to teach students how to do a lifelong physical exercise, so that students leave the school education can still be based on subjective and objective conditions, Engaged in active and effective physical exercise, so that it will benefit for life.

\section{The Problem of Consciousness and Compulsiveness in Physical Education}

At present, China's physical education teaching often used in the teaching model is: teachers in accordance with their own teaching plan and the main sense of teaching, teachers how to say, how students do. In the whole process of physical education, teachers are promoters, organizers, commanders and leaders, is a veritable subject; and students are under the supervision of teachers to learn training, in the object position. This model is an effective teaching mode for middle and primary school students who are poor in their ability of knowledge and self-control. However, for college students, especially those with independent ability and independent opinion, this kind of physical education It is questionable whether the model is suitable. The physical education teaching in colleges and universities should 
establish a student - oriented, student - centered, sports centered sports teaching system, absorb new sports teaching theories and concepts, update the traditional teaching mode, and fully mobilize students' enthusiasm and initiative, So that it voluntarily into the physical exercise activities.

\section{Strengthening the Research on the Teaching Object of Physical Education}

Educational theory of a thorough analysis of "object" is the basis for the implementation of effective education. Ordinary colleges and universities of physical education object is an ordinary college students, this type of specific population for physical education, must be in-depth understanding of its characteristics, so that the teaching is targeted. We believe that the general college physical education should be clear the following three differences: First, the difference between college students and primary and secondary school students. College students and other age groups, compared with the idea of active, easy to accept new things, thirst for knowledge, hope "know why", strong group, activities and other characteristics. Therefore, the physical education of college students should be based on the physiological characteristics of college students at this stage, in order to have a needle. Second is the difference between modern college students and college students in the 1970s and 1980s. Modern college students in the seventies and eighties than the students in terms of more self-awareness and self-awareness, the mandatory requirements of a strong rebellious, easy to produce direct or indirect confrontation, modern college physical education teaching both in the guiding ideology, Teaching forms, teaching methods and other aspects cannot follow the seventies and eighties that set, should be changed and innovation, in order to have the development of the times. Third is the difference between college students and professional athletes or sports faculties. The purpose of physical education in ordinary colleges and universities is not to train athletes, nor to train physical education teachers or sports professionals, but through physical education to develop students' sports ability and improve the health of students for their lifelong physical exercise lay the foundation. Therefore, the purpose of college students' sports tasks, curriculum settings, the choice of teaching methods, and the development of test standards should be different sports colleges and professional sports teams should be around the university sports tasks and goals to determine, in order to have effect.

\section{REFLECTIONS ON THE DEVELOPMENT OF MODERN SPORTS AND THE REFORM OF PHYSICAL EDUCATION IN COLLEGES AND UNIVERSITIES}

With the development of society and the development of sports, people have a deeper understanding of the nature and function of sports. New ideas and new ideas are emerging. The reform of university sports should adapt to the renewal and development of modern sports thought. , So that college sports to meet the needs of social development.

\section{A. Modern Sports Emphasize More on the Health of the Movement}

With the development of science and technology and the depth of understanding of sports, people have changed some of the traditional concept of sports, began to realize: "exercise does not mean that must be conducive to health, unscientific movement but will be detrimental to health." Especially those who do not meet the scientific, excessive exercise or professional training with the nature of the form of sports, the human body is often harmful. Many experts at home and abroad that the future exercise to weak development, with a moderate, step by step physical exercise to replace the unscientific large amount of exercise training. In view of the above point of view, in the reform of college physical education, should gradually reduce the uniform, uniform specifications of the activities, vary from person to body with a specific movement, exercise time and exercise intensity, to improve the scientific exercise, The health level, emphasizing the health of exercise.

\section{B. Modern Sports Emphasize "Dualism of Mind and Body"}

In the 1990s, the World Health Organization (WHO) proposed a new concept of health, which measures the health of a person with "physical health, mental health, good morality and good social adaptability" and "threedimensional health", disease-free or healthy. People are fully aware of the mental health is an important part of health. University students are in a rapidly changing era, college students face competition is full of competition, coupled with the Chinese nation is a biased towards the nation, the psychological health of the phenomenon is very prominent The College students are not healthy, not only will affect their study and life in school, but also will directly affect the development of their lifelong. Therefore, pay attention to the mental health of college students, has a very important practical significance. The process of physical education should overcome the influence of "physical education thought" and "skill education thought". It should not only develop physical fitness and improve athletic skills as the sole purpose, but should regard "mental health" as an important factor to improve the physical health of college students. In addition to emphasizing physical education in sports to relax the psychological adjustment, the role of entertainment, but also through effective means to teach students the necessary psychological health knowledge, so that it can be timely on their own psychological effective health care, So as to improve the psychological resistance of college students, so that it can correctly face the frustration and difficulties in life, improve the level of mental health.

\section{Modern Sports Emphasize More on Entertainment}

With the development of society and the development of sports, the entertainment function of sports has been paid more and more attention. Sport is more oriented to society and facing the family. People more from the sports to enter the type of participation, "sports is a means of physical and mental health, but also the means of music", which is the modern concept of sports. Especially in China after the implementation of the weekend, people's leisure time 
increased, and sports have become a healthy and happy to spend an important part of leisure time. It can be seen that the purpose of people participating in sports activities has evolved from a simple physical fitness to a part of social life. We found in the survey results: $97.6 \%$ of the students on the "sport is no longer a simple physical fitness, but also the introduction of spiritual pursuit and cultural pursuit and the connotation of social activities" agreed. In today's social development to give sports more rich connotation, if the physical education is still in accordance with the running, gymnastics, boxing outline content, to old, repetitive, mechanical teaching system to set up physical education, is far from being able to meet the lay Lifelong sports base, enrich the future needs of cultural and sports life. Therefore, only in the university sports teaching to add new sports programs, to be able to adapt to the future social-economic, social life development.

\section{Modern Sports Emphasize More on Practicality}

The exercise value of sports can only be embodied by human practice. The physical activity, skills, or physical activity activities that college students have learned during their studies at the university should be adapted to the characteristics of future occupations and living environment and can play a role in their physical exercise after entering society. Therefore, the current university sports curriculum in the set, should consider the social value of sports projects. We use the form of questionnaire to understand the favorite sporting events of college students and find that the top ten sports items that are popular with students are: badminton, tennis, table tennis, mountain climbing, swimming, sports dance, tourism, basketball Run or walk, aerobics. It can be seen that today's college students love the sport not only has a very obvious flavor of the times, but also fully reflects the movement of social value of the project transfer law. Therefore, students in the choice of sports focus on the more purpose. Through the study of students' favorite sports, we also found that college students have the following rules for the choice of sports: one is to focus on projects that do not depend on the facilities of a particular sports venue. Such as soccer, soccer, volleyball and other sports that have not been able to enter the top ten, it does not mean that they no longer love these projects, but these projects are limited by the venue, into the community; continue to engage in these projects Conditions and opportunities less. Second is the emphasis on personal sports. This is because the postgraduation workplace students scattered, it is difficult to organize groups to exercise, and on the contrary, personal sports have greater freedom and flexibility. Third is the emphasis on non-competitive sports. The survey shows that college students are included in the top ten sports, mostly fitness and entertainment-based non-competitive sports. Through the above analysis, we believe that the establishment of university physical education curriculum should take into account the exercise value of the project and the value of social transfer, so that college students in the school of sports knowledge, skills and skills into the community can be practical application for life for sports Exercise laid the foundation.

\section{E. People's Understanding of Sports Has Reached a New Level}

Self-physical education that "from their own needs, in accordance with my own wishes and hobbies, I have consciously spontaneously engaged in 'the body of my' activities" to achieve "to improve the efficiency of life, to achieve the purpose of scientific life" The It can be seen that the self-spontaneous self-sports view of "self-investment, self-exercise and self-benefiting" conforms to the inevitable trend of social and human development. Because there is no self-motive and self-needs, there will be no real sports. The university period is the critical period of the transition from "education sports" to "self-sports", and cultivating students' self-improvement ability is an important link for laying the foundation for lifelong sports. Therefore, it is necessary to teach students the skills and skills of self-exercise in selfexercise during the university, and to teach students the knowledge and methods of scientific physical exercise in various natural conditions and social life. It is necessary to cultivate the consciousness of "self-sports".

\section{CONCLUSION}

In summary, the university physical education should be the core of physical education to the healthy development of students for the purpose of promoting students to carry out extracurricular sports activities to promote the formation of campus sports culture, to create a "conscious to the scientific exercise "atmosphere, for its graduation into the community of life-long physical training to lay the skills and the basis of consciousness. Therefore, the reform of college physical education needs to be bold and innovative in the curriculum and teaching form, so that the teaching of physical education can be developed in an interesting, relaxed, free and entertaining direction to stimulate students' interest in sports activities and promote students to actively and voluntarily participate in sports Exercise, master their favorite sporting skills, skills, learn the knowledge and methods of healthy life, in order to improve the quality of life in the future, lifelong engaged in physical exercise and health lay the foundation.

\section{REFERENCES}

[1] Zou Jijiao.For the 21st century Chinese School Sports [M]. Dalian: Dalian University of Technology Press, 2000.

[2] Ji Liu. Physical Education Outlook [M]. Shanghai: East China Normal University Press, 2001.

[3] Yang Guiren. China's School Sports Work Development [J]. Sports Science, 2000 (3).

[4] Hu Xiaoming. New Era of Sports Social Function Changes [J]. Sports Culture Guide, 2003 (3).

[5] Chen Qi. The Fundamental Goal of School Sports [J]. Journal of Physical Education, 2003 (6). 